\title{
In-vitro development of zygotes from superovulated prepubertal and mature gilts
}

\author{
C. A. Pinkert* + , D. L. Kooyman*, A. Baumgartner* and D. H. Keisler* \\ *Department of Animal Sciences, University of Missouri, Columbia, Missouri 65211, USA; and \\ †Embryogen, Inc., Athens, Ohio 45701, USA
}

\begin{abstract}
Summary. Ten prepubertal and 8 mature gilts were superovulated with PMSG and $\mathrm{hCG}$, and inseminated with fresh boar semen. Zygotes were surgically recovered from oviducts 54-60 h after hCG. One and 2-cell zygotes were randomly allotted to Medium PL (modified BMOC-3 supplemented with 0.1 mM-EDTA and $1.5 \%$ BSA) or Medium $G$ (Medium PL without pyruvate or lactate). Eggs were washed twice in medium, and placed in microdrops of medium overlaid with silicon oil for culture in an humidified $5 \% \mathrm{CO}_{2}, 5 \% \mathrm{O}_{2}, 90 \% \mathrm{~N}_{2}$ environment, then observed daily for 6 days. Development of eggs was dependent $(P<0.001)$ on the interactive effects of age of gilt (prepubertal versus mature) and medium type (PL versus $\mathrm{G}$ ) used in culture. A greater proportion of eggs cultured in Medium $\mathrm{G}$ developed further than did eggs in Medium PL $(P<0.001)$. Additionally, a greater proportion of eggs from mature gilts developed further than did eggs from prepubertal gilts $(P<0 \cdot 02)$. We suggest that these results provide evidence that zygotes resulting from superovulation regimens of prepubertal gilts do not possess the same capacity for in-vitro development as do zygotes from pubertal gilts.
\end{abstract}

Keywords: zygote; blastocyst; prepubertal; pigs

\section{Introduction}

Previous research has focussed on the hypothalamic, pituitary, ovarian and uterine components associated with the failure of superovulated prepubertal gilts to maintain pregnancy (Rampacek et al., 1976, 1985; Puglisi et al., 1979; Lutz et al., 1984; Pinkert et al., 1988). Zygote viability independent of the influences of the female reproductive tract has not been investigated.

The sexual maturity of the donor pig has been a consideration when obtaining zygotes for culture or microinjection. Superovulation regimens are dependent upon specific timing of the oestrous cycle in the mature gilt or sow. Zygote yields obtained from U.S. commercial crossbred prepubertal gilts induced to ovulate are similar to yields from mature gilts. However, when transferred to mature cyclic gilts, zygotes from prepubertal donors do not routinely develop to term (unpublished observations; J. Hoover, unpublished observations).

Research involving the use of 1- and 2-cell pig zygotes, in addition to the study of basic embryology, includes microinjection of foreign genes to produce transgenic pigs. To maximize transgenic research efficiency, it is essential to maintain ova in supportive media from the time they are obtained from a donor animal until they are returned to a recipient. This has importance in both short-term culture at the present time, and with potential long-term culture leading to non-surgical transfer of blastocysts in the future.

The development of media for in-vitro culture of mouse zygotes has been established (Brinster, 1972). However, the successful in-vitro culture of pig zygotes has remained more difficult with the 
exception of co-culture techniques (Kuzan \& Wright, 1982; Allen \& Wright, 1984). Studies aimed at characterizing a medium for in-vitro culture of 4-cell pig eggs have provided evidence that pyruvate and lactate may be detrimental to egg development (Davis \& Day, 1978). The purpose of this study, therefore, was to compare in-vitro development of zygotes obtained from superovulated prepubertal and mature gilts cultured in two media formulations.

\section{Materials and Methods}

The 10 prepubertal and 8 mature crossbred gilts were obtained from the University of Missouri pig research farms, and placed in individual pens in a total confinement unit. Ovulation was induced by an injection of 1500 i.u. PMSG (s.c.) followed $80 \mathrm{~h}$ later by 500 i.u. hCG (i.m.). The pubertal gilts were synchronized by injection of PMSG on Days 15-17 of the 2nd or 3rd oestrous cycle. Pigs were checked twice daily for behavioural oestrus with a boar. Pigs were then artificially inseminated or naturally mated at 12-h intervals beginning $24 \mathrm{~h}$ after the onset of standing oestrus, continuing through oestrus or until the morning of ova recovery.

At 58-64 h after hCG, the reproductive tract was exposed by mid-ventral laparotomy. After observing ovaries for the presence of follicular and luteal structures, ova were flushed from oviducts using phosphate-buffered saline (PBS) containing $0 \cdot 4 \%$ bovine serum albumin (Sigma, St Louis, MO, USA). Criteria for inclusion of 1 -cell eggs included the visual identification of supernumerary spermatozoa and polar bodies. One and 2-cell eggs were randomly allocated to modified BMOC-3 Medium (Brinster et al., 1985) supplemented with $0.1 \mathrm{mM-EDTA}$ and $1.5 \%$ BSA (designated Medium PL), or Medium PL without pyruvate and lactate (designated Medium G). Eggs were washed twice in the final culture medium and placed in microdrops of media overlaid with silicon oil for culture, then incubated in an humidified $5 \% \mathrm{CO}_{2}, 5 \% \mathrm{O}_{2}, 90 \% \mathrm{~N}_{2}$ environment (Pinkert, 1987). Ova were observed every $24 \mathrm{~h}$ for 6 days (Day 1 of culture began $60 \mathrm{~h}$ after hCG). Eggs not transferred to recipient gilts were stained with Hoechst 33342 (Sigma) on Day 6 or 8 of culture to verify cell number by nuclear fluorescence (Pursel et al., 1985).

Data were statistically analysed by analysis of variance procedures for categorical models (Grizzle et al., 1969) using the program CATMOD (1985: SAS Institute Inc., Cary, NC, USA).

\section{Results}

Eggs were collected from 10 prepubertal (184 eggs) and 8 mature (113 eggs) gilts and placed in invitro culture. Eggs were randomly assigned for incubation in Medium G ( 92 eggs from prepubertal gilts, 61 from mature gilts) or Medium PL (92 eggs from prepubertal gilts, 52 from mature gilts) as depicted in Table 1.

Table 1. Development of pig zygotes after in-vitro incubation for 6 days*

\begin{tabular}{|c|c|c|c|c|c|c|c|c|}
\hline \multirow[b]{2}{*}{ Status } & \multirow[b]{2}{*}{ Medium } & \multicolumn{2}{|c|}{ Day 1} & \multicolumn{5}{|c|}{ Development by Day 6} \\
\hline & & $1 \mathrm{C} / 2 \mathrm{C}$ & Total & $3-4 \mathrm{C}$ & $6-8 \mathrm{C}$ & Morula & Blastocyst & $\mathrm{D} / \mathrm{F}$ \\
\hline Prepubertal & G & $65 / 27$ & 92 & 62 & 21 & 14 & 8 & 57 \\
\hline Prepubertal & PL & $65 / 27$ & 92 & 29 & 25 & 16 & 1 & 59 \\
\hline Mature & G & $36 / 25$ & 61 & 46 & 29 & 22 & 5 & 21 \\
\hline Mature & PL & $29 / 23$ & 52 & 20 & 6 & 3 & 0 & 39 \\
\hline
\end{tabular}

*Development was defined as to or through the most advanced cleavage stage achieved by Day 6 of culture, or before egg degeneration or fragmentation occurred. Abbreviations: $C$, cell; $D / F$, total number of eggs that degenerated or fragmented on or before Day 6 of culture.

A greater proportion $(P<0.001)$ of 1 - and 2-cell eggs cultured in Medium $\mathrm{G}$ developed to or through the 3-4-cell, 6-8-cell, morula and blastocyst stages than did eggs cultured in Medium PL.

In contrast, the effects of age of gilt on egg development were less obvious. Although a greater proportion of 1-2-cell eggs from mature gilts developed to or through the 3-4-cell, 6-8-cell, and morula stages than did eggs from prepubertal gilts $(P<0.02)$, equal proportions of eggs from prepubertal and mature gilts developed to the blastocyst stage $(P>0.05)$. However, the total 
proportion of eggs from prepubertal gilts which developed to the morula and blastocyst stages were contributed by only 2 of the 10 prepubertal gilts.

Interactive effects of type of culture medium used to incubate eggs and the age of egg donors were found $(P<0.001)$. A greater proportion of eggs from mature gilts cultured in Medium $\mathrm{G}$ developed to or through the 3-4-cell, 6-8-cell, morula and blastocyst stages than did eggs from mature gilts cultured in Medium PL or eggs from prepubertal gilts cultured in Media G or PL.

\section{Discussion}

Development of 1- and 2-cell pig zygotes was proportionally greater in Medium $\mathrm{G}$ than in Medium PL. There are three possible explanations for this observation: (1) Medium $G$ was better for egg development than was Medium PL, (2) the pyruvate and lactate contained in Medium PL were detrimental to egg development as suggested by Davis \& Day (1978), or (3) the differences were due to favourable effects of Medium G and detrimental effects of Medium PL.

From our earlier experiments, it was surprising that the effect of age of gilt on egg development was not more dramatic. However, these results support an effect of age of egg donor on egg development as well as provide evidence that great variation can exist between animals in development of their eggs in vitro.

Because of the interactive effects of type of culture medium used and the age of egg donors, we infer that Medium $G$ was the least detrimental to the development of eggs from mature gilts. Interpretations of the effects of type of medium on in-vitro development of eggs from prepubertal gilts was dependent on a consideration of the stage of development. Medium $G$ may have been most favourable (or least detrimental) to the development of eggs from prepubertal gilts to the 3-4-cell or blastocyst stages.

Similar to our culture of pig eggs, Wright et al. (1976) reported on the efficacy of several media used to culture eggs collected 48-72 h after oestrus from mature and prepubertal ewes. They observed a decreased tendency for eggs to develop in vitro when the eggs were obtained from the prepubertal ewes. In parallel, eggs obtained from calves induced to ovulate degenerated more rapidly and were less viable than eggs from mature cows (Seidel et al., 1971). The authors concluded that the exposure of the eggs to the prepubertal reproductive tract was detrimental to their survival. However, in the present study, as in sheep (Wright et al., 1976), it is unlikely that the short exposure time of the eggs to the prepubertal oviduct or uterus was the sole influence on egg viability. Rather, it appears more likely that the eggs themselves are inherently less viable in a given environment.

The most successful medium reported for use in culture of pig eggs was a modified Krebs-Ringer bicarbonate (KRB) solution with glucose and BSA $(0.4$ to $1.5 \%)$, with an increasing effectiveness as the concentration of BSA increased in the absence of pyruvate and lactate (Davis \& Day, 1978). In the present study, a medium based on BMOC-3 was used, which is similar to KRB supplemented with glucose and BSA, and which was used successfully and routinely for the culture of 1- and 2-cell mouse zygotes to the blastocyst stage.

These results support our hypothesis that zygotes from prepubertal gilts do not possess the equivalent in-vitro development potential of zygotes from mature gilts. Development of eggs from prepubertal and mature gilts was similar to the blastocyst stage but not to the morula stage, perhaps suggestive of a transitional block from the morula to the blastocyst stage in mature gilts. Alternatively, zygotes from prepubertal and mature gilts have different requirements for development or different rates of development. In light of the 2 -fold difference in egg degeneration between prepubertal and mature gilts and the general cessation of further development beyond Day 6 of culture (unpublished data) we suggest that the developmental potential or differential requirements of prepubertal and mature gilts are the most likely underlying mechanisms in the interpretation of our results. 
Our data are in agreement with other studies in which improved zygote development occurred when pyruvate and lactate were omitted from the culture medium for eggs of mature gilts (Davis \& Day, 1978; Davis, 1985). We suggest that Medium G may be suitable for long-term ( $>72 \mathrm{~h}$ ) invitro development of mature pig ova. However, the subsequent development in vivo of zygotes cultured for extended periods in Medium G must be determined. As suggested by studies using sheep, in-vitro development does not necessarily mirror in-vivo developmental capacity (Gandolfi \& Moor, 1987).

Co-culture techniques have also been used for in-vitro cultivation of domestic animal ova. The viability of bovine morulae was maintained for nearly 2 weeks on a uterine-cell monolayer (Voelkel et al., 1985). Similar studies were successful in culturing pig eggs on fibroblast (Kuzan \& Wright, 1982) or endometrial (Allen \& Wright, 1984) monolayers. However, these systems require the establishment and maintenance of cells in culture which are expensive and laborious efforts in comparison to direct culture in simple media.

More research is needed before cultivation of 1- and 2-cell pig eggs is efficient for in-vitro maturation to the blastocyst stage. Such methodology will greatly benefit the evaluation of ovum viability in numerous experimental manipulations as well as practical applications of egg transfer.

This work was supported by grants from the University of Missouri Food for the 21st Century Program and USDA 87-CRSR-2-3147. We thank T. J. Dyer, G. J. Vergara and A. Riecke for valuable assistance.

\section{References}

Allen, R.L. \& Wright, R.W. (1984) In vitro development of porcine embryos in coculture with endometrial cell monolayers or culture supernatants. J. Anim. Sci. 59, 1657-1661.

Brinster, R.L. (1972) Cultivation of the mammalian egg. In Growth, Nutrition and Metabolism of Cells in Culture, vol. 2, pp. 25I-286. Eds G. Rothblat \& V. Cristofalo. Academic Press, New York.

Brinster, R.L., Chen, H.Y., Trumbauer, M.E., Yagle, M.K. \& Palmiter, R.D. (1985) Factors affecting the efficiency of introducing foreign DNA into mice by microinjecting eggs. Proc. natn. Acad. Sci. USA 82, 4438-4442.

Davis, D.L. (1985) Culture and storage of pig embryos. $J$. Reprod. Fert., Suppl. 33, 115-125.

Davis, D.L. \& Day, B.N. (1978) Cleavage and blastocyst formation by pig eggs in vitro. J. Anim. Sci. 46, 1043-1053.

Gandolfi, F. \& Moor, R.M. (1987) Stimulation of early embryonic development in the sheep by co-culture with oviduct epithelial cells. J. Reprod. Fert. 81, 23-31.

Grizzle, J.E., Starmer, C.F. \& Koch, G.G. (1969) Analysis of categorical data by linear models. Biometrics $25,489-504$.

Kuzan, F.B. \& Wright, R.W. (1982) Observations on the development of bovine morulae on various cellular and noncellular substrata. J. Anim. Sci. 54, 811-816.

Lutz, J.B., Rampacek, G.B., Kraeling, R.R. \& Pinkert, C.A. (1984) Serum luteinizing hormone and estrogen profiles before puberty in the gilt. J. Anim. Sci. 58, 686-691.

Pinkert, C.A. (1987) Gene transfer and the production of transgenic livestock. Proc. U.S. Anim. Health Assn 91, 129-141.
Pinkert, C.A., Rampacek, G.B. \& Kraeling, R.R. (1988) Serum concentrations of prolactin, oestrogen and LH during the perioestrous period in prepubertal gilts induced to ovulate and mature gilts. J. Reprod. Fert. 83, 471-478.

Puglisi, T.A., Rampacek, G.B., Kraeling, R.R. \& Kiser, T.E. (1979) Corpus luteum susceptibility to prostaglandin $F_{2 a}\left(P G_{2 a}\right)$ luteolysis in hysterectomized prepubertal and mature gilts. Prostaglandins 18, 257-264.

Pursel, V.G., Wall, R.J., Rexroad, C.E., Jr, Hammer, R.E. \& Brinster, R.L. (1985) A rapid whole-mount staining procedure for nuclei of mammalian embryos. Theriogenology 24, 687-691.

Rampacek, G.B., Kraeling, R.R. \& Ball, G.D. (1976) Luteal function in the hysterectomized prepuberal gilt. J. Anim. Sci. 43, 792-794.

Rampacek, G.B., Kraeling, R.R. \& Pinkert, C.A. (1985) Regression of induced corpora lutea by human chorionic gonadotropin in prepuberal gilts. J. Anim. Sci. 60, 1040-1044.

Seidel, G.E., Jr, Larson, L.L., Spilman, C.H., Hahn, J. \& Foote, R.H. (1971) Culture and transfer of calf ova. $J$. Dairy Sci. 54, 923-926.

Wright, R.W., Jr, Anderson, G.B., Cupps, P.T., Drost, M. \& Bradford, G.E. (1976) In vitro culture of embryos from adult and prepubertal ewes. J. Anim. Sci. 42, 912-917.

Voelkel, S.A., Amborski, G.F., Hill, K.G. \& Godke, R.A. (1985) Use of a uterine-cell monolayer culture system for micromanipulated bovine embryos. Theriogeno$\log y \mathbf{2 4}, 271$, abstr. 